\title{
Enhanced infection control interventions reduced catheter-related bloodstream infections in the neonatal department of Hung Vuong Hospital, Vietnam, 2011-2012: a pre- and post-intervention study
}

Hang Thi Phan ${ }^{1 \dagger}$, Thuan Huu V $0^{2^{*}+} \mathbb{B}$, Hang Thi Thuy Tran ${ }^{1}$, Hanh Thi Ngoc Huynh ${ }^{1}$, Hong Thi Thu Nguyen ${ }^{1}$ and Truong Van Nguyen ${ }^{1}$

\begin{abstract}
Background: Catheter-related bloodstream infections (CR-BSI) cause high neonatal mortality and are related to inadequate aseptic technique during the care and maintenance of a catheter. The incidence of CR-BSI among neonates in Hung Vuong Hospital was higher than that of other neonatal care centres in Vietnam.

Methods: An 18-month pre- and post-intervention study was conducted over three 6-month periods to evaluate the effectiveness of the intervention for CR-BSI and to identify risk factors associated with CR-BSI. During the intervention period, we trained all nurses in the Department of Neonatology on BSI preventive practices, provided auditing and feedback about aseptic technique during catheter care and maintenance, and reorganised preparation of total parenteral nutrition. All neonates with intravenous catheter insertion $\geq 48 \mathrm{~h}$ in the pre- and postintervention period were enrolled. A standardised questionnaire was used to collect data. Blood samples were collected for cultures. We used Poisson regression to calculate rate ratio (RR) and 95\% confidence interval (CI) for CR-BSI incidence rates and logistic regression to identify risk factors associated with CR-BSI.

Results: Of 2225 neonates enrolled, 1027 were enrolled in the pre-intervention period, of which 53 CR-BSI cases occurred in 8399 catheter-days, and 1198 were enrolled in the post-intervention period, of which 32 CR-BSI cases occurred in 8324 catheter-days. Incidence rates of CR-BSI significantly decreased after the intervention (RR $=0.61$, $95 \% \mathrm{Cl}$ 0.39-0.94). Days of hospitalisation, episodes of non-catheter-related hospital-acquired infections, and the proportion of deaths significantly decreased after the intervention $(p<0.01)$. The CR-BSI was associated with days of intravenous catheter (odds ratio $[\mathrm{OR}]=1.05,95 \% \mathrm{Cl} 1.03-1.08)$, use of endotracheal intubation $(\mathrm{OR}=2.27,95 \% \mathrm{Cl}$ 1.27-4.06), and intravenous injection ( $\mathrm{OR}=8.50,95 \% \mathrm{Cl} 1.14-63.4)$.

Conclusions: The interventions significantly decreased the incidence rate of CR-BSI. Regular refresher training and auditing and feedback about aseptic technique during care and maintenance of catheters are critical to reducing CR-BSI.
\end{abstract}

Keywords: Infection control, Catheter, Bloodstream infection, Intervention, Aseptic technique, Vietnam

\footnotetext{
* Correspondence: vo.huuthuan@yahoo.com

†Phan Thi Hang and Vo Huu Thuan contributed equally to this work.

${ }^{2}$ Hung Vuong Hospital, 128 Hong Bang Street, District 5, Ho Chi Minh City,

Vietnam

Full list of author information is available at the end of the article
}

(c) The Author(s). 2020 Open Access This article is distributed under the terms of the Creative Commons Attribution 4.0 International License (http://creativecommons.org/licenses/by/4.0/), which permits unrestricted use, distribution, and

reproduction in any medium, provided you give appropriate credit to the original author(s) and the source, provide a link to the Creative Commons license, and indicate if changes were made. The Creative Commons Public Domain Dedication waiver (http://creativecommons.org/publicdomain/zero/1.0/) applies to the data made available in this article, unless otherwise stated. 


\section{Introduction}

Intravenous catheter insertion is vital to managing critically ill patients, but it may involve a high risk of catheter-related bloodstream infections (CR-BSI). Bloodstream infection, usually caused by multi-drug-resistant organisms (MDRO), may be fatal and result in a long hospital stay and high treatment costs [1]. The most common pathogens of CR-BSI are coagulase-negative staphylococci, Staphylococcus aureus, and Enterococcus spp. [2, 3]. The incidence rates of CR-BSI range from 3.8-11.3 per 1000 neonate-days in neonatal intensive care units in developed countries, accounting for $30 \%$ of hospital-acquired infections (HAI) in paediatric hospitals $[1,4,5]$. The rates are usually much higher in developing countries due to hospital overload, insufficient medical equipment, and unsafe aseptic practices by healthcare workers [6]. Guembe et al. showed that the CR-BSI rate in developing countries was $18.7 \%$, while that of the United States was $0.1 \%$ [7]. Studies have shown several basic infection control practices such as hand hygiene, skin disinfection, dressing catheter sites, and appropriate intravascular catheters are effective in reducing CR-BSI [8-11].

In Vietnam, CR-BSI rates are relatively high in neonatal intensive care units. At Children's Hospital No. 1, Ho Chi Minh City in 2005, the CR-BSI rate was 7.5 per 1000 catheter-days, and the BSI from peripheral and central catheters were 6.3 per 1000 patient-days and $15.8 \%$ of total admitted cases, respectively [12].

Hung Vuong Hospital (HVH) is one of the largest tertiary maternity hospitals in Vietnam, with 900 beds and more than 40,000 deliveries annually. Department of Neonatology (DON) of the HVH has 100 beds, including 20 in the neonatal intensive care unit (NICU), where about 120 neonates are admitted each month. However, only one doctor and two nurses are available $24 / 7$ in the NICU. It is a heavy workload to take care of 20 severe ill neonates, including preparing total parenteral nutrition (TPN), in NICU. Patient overload and understaffing are high in $\mathrm{HVH}$ but most severe in DON.

In 2007, a study conducted in HVH found that the proportion of intravenous catheter utilisations among the total admitted neonates in DON was $34.6 \%$, but the rate of hospital-acquired bloodstream infection (BSI) in the DON was 15.3 per 1000 catheter-days. The proportion of nurses in the DON who complied with aseptic techniques during catheter placement was unacceptably low (25\%) [13]. In addition, TPN was prepared in patient rooms, not in the Department of Pharmaceuticals (DOP), as the World Health Organization (WHO) recommends.

At $\mathrm{HVH}$, the high rate of CR-BSI could result from factors related to characteristics of patients, types of catheters, and aseptic techniques of healthcare workers during the placement and maintenance of catheters.
Because of limited resources to address all these factors, we intervened in compliance with nurses' aseptic techniques in DON together with relocating TPN preparation to DOP. The aims of this study were to (i) assess the incidence and causative organisms of CR-BSI, (ii) evaluate the effectiveness of the interventions, and (iii) identify the risk factors associated with CR-BSI.

\section{Methods}

\section{Descriptive of the intervention}

The study was conducted from March 2011 through August 2012 in three succeeding 6-month periods: pre-intervention (01.3.2011-31.8.2011), intervention (01.9.2011-29.02.2012), and post-intervention (01.3.2012-31.8.2012). During the intervention period, we implemented the following: (i) training for all nurses of DON on BSI preventive practices; (ii) auditing of and feedback about aseptic technique during care and maintenance of catheters; and (iii) reorganising the procedure of TPN preparation by preparing TPN under a laminar airflow hood and relocating to a clean room in DOP.

In all, 71 nurses were trained in three one-day handson training courses. During the course, intravenous catheter insertion technique was first reviewed. This was followed by a demonstration and practice of handwashing, aseptic technique, maximal sterile barrier protection (e.g. head caps, facemasks, sterile body gowns, and sterile gloves), antiseptic use, skin preparation, and catheter care and maintenance. Training materials for the BSI preventive practices were adapted from the Centers for Disease Control and Prevention (CDC) Guidelines for the Prevention of Intravascular Catheter-Related Infections [1]. All nurses of DON were requested to take a pre- and post-test, and they had to obtain at least $80 \%$ of the maximum score on the post-test. The auditing and feedback were recorded and reported in daily meetings in DON to maximise the nurses' learning, knowledge, and skills.

\section{Collection of data}

Definitions of CR-BSI were slightly adapted from Horan et al. [14], as summarised in Table 1. During the pre- and post-intervention periods, all neonates with intravenous catheters in DON were enrolled in our study. We collected demographic details, health information at birth, time and duration of signs and symptoms of infections, duration of intravenous catheter insertion and hospitalisation, and risk factors of CR-BSI (e.g. gestational age, gender, weight at birth, preterm birth, congenital diseases, methods of delivery, duration of hospitalisation, intravenous injection, blood infusion, parenteral nutrition, endotracheal intubation, duration of ventilator, duration of umbilical intravenous infusion, and HAI) using a standardised questionnaire. We 
Table 1 Definitions of catheter-related bloodstream infections among neonates with intravenous catheter insertion for $\geq 48 \mathrm{~h}$ in Hung Vuong Hospital, Vietnam

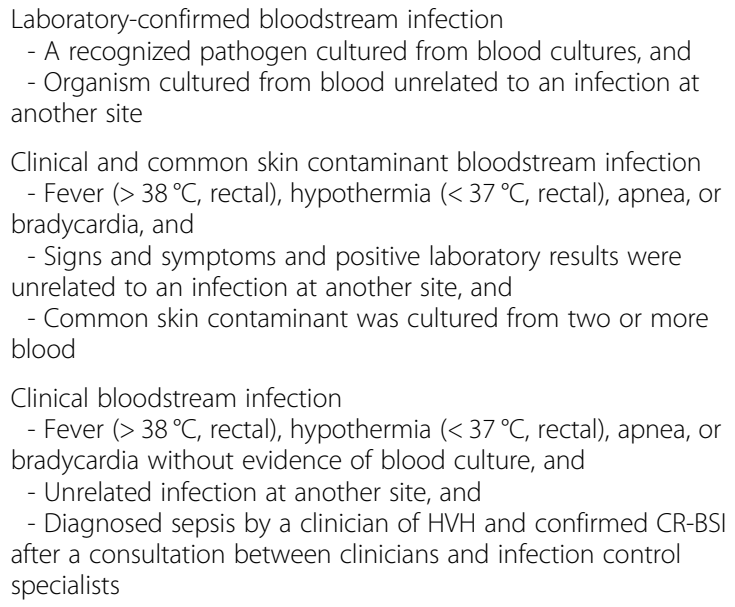

excluded neonates with confirmed BSI at admission or those with intravenous catheter insertion of less than $48 \mathrm{~h}$.

All members of the study team were trained in data collection. Data were processed weekly to ensure completeness and internal consistency.

Blood samples were collected for cultures to detect commonly recognised pathogens (e.g. coagulase-negative staphylococci, Staphylococcus aureus, Enterococcus spp., Stenotrophomonas maltophilia, Escherichia coli, and Acinetobacter spp.) based on the standard operating procedure of HVH. A multi-drug-resistant (MDR) isolate "is resistant to at least one antibiotic in three or more drug classes" [15]. When antibiotic-resistant bacteria were detected in the $\mathrm{HVH}$ laboratories, six antimicrobial classes (aminoglycosides, $\beta$-lactam, carbapenems, cephalosporins, fluoroquinolones, and sulbactam) were tested to confirm MDRO based on the Clinical \& Laboratory Standards Institute and also referred to laboratory tests approved by the Food and Drug Administration [16].

\section{Analysis of data}

Data were analysed using $\mathrm{R}$ software (Epi, BMA, and car packages). Chi-square, Fisher's exact test, t-test, or Mann Whitney U test was used to compare the characteristics of neonates between the pre- and post-intervention periods with a significance level of $<0.05$. Poisson regression was used to calculate rate ratio (RR) and $95 \%$ confidence interval (CI) for CR-BSI incidence rates. Odds ratio (OR) and 95\% CI were used to identify risk factors associated with the CR-BSI by using logistic regression models. Model building and selection for CR-BSI were based on Bayesian Model Average. Goodness-of-fit of the models was accessed by Pearson chi-square and deviance statistic. We used 1000 bootstrap replicates to determine more important variables in the final model.

\section{Results}

Results of training on BSI preventive practices for the 71 nurses of DON and the auditing and feedback of aseptic technique

The proportion of nurses with adequate knowledge was 92\% (65) after the training compared with 30\% (21) before the training. In the practical section before the training, $28 \%$ (20) of the nurses did not comply with handwashing and aseptic technique, 21\% (15) had faults with skin disinfection, 17\% (12) touched the syringes' needles during withdrawing liquid medicines, and 13\% (9) used aseptic dressings for the catheter inadequately. After the training, the 65 nurses adhered to handwashing and aseptic technique during the insertion of intravenous catheters and maximal sterile barrier precautions. About 8\% (6) were retrained on the BSI preventive practices before obtaining adequate knowledge.

During the intervention period, 4147 peripheral intravenous catheters were observed. All the catheters were located in appropriate positions, and 96\% (3998) were cared for and maintained appropriately at catheter sites. Of the 4\% (149 catheters with inappropriate care and maintenance), $2 \%$ (66) were due to oedema at catheter sites, $1.5 \%$ (61) used inappropriate catheter dressings, and $0.5 \%$ (22) did not remove unused intravenous catheters. Among 300 umbilical catheters observed, 3\% (9) were placed for more than 14 days.

\section{Characteristics of neonates in the pre- and post- intervention periods}

Among the 2551 neonates with intravenous catheter insertion admitted to the DON in the study period, 2225 met inclusion criteria, of which 1027 and 1198 were enrolled in the pre- and post-intervention periods, respectively. The difference of characteristics of gestational age, gender, weight at birth, premature birth, neonates with congenital diseases, endotracheal intubation, ventilator days, blood infusion, reasons for intravenous catheter insertion of blood infusion and intravenous injection, episodes of HAI, duration of hospitalisation, and status of discharge among neonates between pre-and postintervention periods were significant $(p<0.05)$. There were no significant differences of days of age at catheter insertion and total parenteral nutrition among neonates between the two periods (Table 2).

During the study period, 16,723 catheter-days were included in the final analysis, of which 8324 were included in the post-intervention period. After the intervention, the CR-BSI rate significantly decreased from 6.31 infections per 1000 catheter-days in the pre-intervention period to 3.84 in the post-intervention period $(R R=0.61$, 95\% CI 0.39-0.94, Table 3). The characteristics showed in Table 2 were used for model building and selection; however, no potential confounding factors were found in 
Table 2 Characteristics of neonates with intravenous catheter insertion for $\geq 48 \mathrm{~h}$ in pre- and post-intervention periods in Hung Vuong Hospital, Vietnam

\begin{tabular}{|c|c|c|c|c|}
\hline Characteristics & $\begin{array}{l}\text { Pre-intervention } \\
\text { neonate }(n=1027)\end{array}$ & $\begin{array}{l}\text { Post-intervention } \\
\text { neonate }(n=1198)\end{array}$ & $\begin{array}{l}\text { Total } \\
(n=2225)\end{array}$ & $p$-value \\
\hline Gestational age (mean, SD) & $33.6 \pm 3.6$ & $34.7 \pm 3.7$ & $34.3 \pm 3.7$ & $<0.001^{\mathrm{a}}$ \\
\hline Gender (n, \%) & & & & $0.04^{b}$ \\
\hline Male & $549(53.5)$ & $694(57.9)$ & $1243(55.9)$ & \\
\hline Female & $478(46.5)$ & $504(42.1)$ & $982(44.1)$ & \\
\hline $\begin{array}{l}\text { Days of age with catheter insertion } \\
\text { (median, range) }\end{array}$ & $1(1,27)$ & $1(1,122)$ & $1(1,122)$ & $0.45^{c}$ \\
\hline Weight at birth (gram, mean, SD) & $2135 \pm 755$ & $2276 \pm 780$ & $2211 \pm 771$ & $<0.001^{\mathrm{a}}$ \\
\hline Methods of delivery (n, \%) & & & & $0.14^{b}$ \\
\hline Vaginal & $568(55.3)$ & $624(52.1)$ & $1192(53.6)$ & \\
\hline Cesarean section & $459(44.7)$ & $574(47.9)$ & $1033(46.4)$ & \\
\hline Premature (<37 weeks, $(\mathrm{n}, \%))$ & $699(68.1)$ & 738 (61.6) & $1437(64.6)$ & $<0.01^{\mathrm{b}}$ \\
\hline $\begin{array}{l}\text { Neonates with congenital diseases } \\
(n, \%)\end{array}$ & $261(25.4)$ & $218(18.2)$ & $479(21.5)$ & $<0.001^{b}$ \\
\hline Endotracheal intubation (n, \%) & $208(20.3)$ & $179(14.9)$ & 387 (17.4) & $<0.01^{b}$ \\
\hline Ventilator days (median, IQR) & $1.5(1.0,3.0)$ & $2.0(1.0,4.5)$ & $2.0(1.0,3.5)$ & $<0.001^{c}$ \\
\hline \multicolumn{5}{|l|}{$\begin{array}{l}\text { Reasons for intravenous catheter } \\
\text { insertion }(n, \%)\end{array}$} \\
\hline Blood infusion & $157(15.3)$ & $133(11.1)$ & $290(13.0)$ & $<0.01^{b}$ \\
\hline Total parenteral nutrition & $1017(99.0)$ & $1177(98.2)$ & $2194(98.6)$ & $0.17^{d}$ \\
\hline Intravenous injection & $783(76.2)$ & $827(69.0)$ & $1610(72.4)$ & $<0.001^{b}$ \\
\hline $\begin{array}{l}\text { Episodes of hospital-acquired } \\
\text { infection (mean, SD) }\end{array}$ & $1.32 \pm 0.59$ & $0.17 \pm 0.46$ & $0.39 \pm 0.66$ & $<0.001^{\mathrm{a}}$ \\
\hline Days of hospitalization (mean, SD) & $15.5 \pm 19.2$ & $12.5 \pm 15.1$ & $13.9 \pm 17.2$ & $<0.001^{\mathrm{a}}$ \\
\hline Status of discharge $(n, \%)$ & & & & $<0.01^{b}$ \\
\hline Death & $113(11.0)$ & $80(6.7)$ & $193(8.7)$ & \\
\hline Cured & $874(85.1)$ & $1070(89.3)$ & $1944(87.4)$ & \\
\hline Hospitalization & $40(3.9)$ & $48(4.0)$ & $88(4.0)$ & \\
\hline
\end{tabular}

$S D$ standard deviation, IQR interquartile range

${ }^{a}$ t-test; ${ }^{b}$ Chi-square test; ${ }^{c}$ Mann Whitney $U$ test, ${ }^{d}$ Fisher's exact test

multivariate Poisson regression (the effects changed less than $10 \%)$.

\section{Characteristics of catheter-related bloodstream infection} cases in the pre- and post-intervention periods

During the study period, we identified a total of 85 CR-BSI cases, of which 53 occurred during the pre-intervention period and 32 occurred in the post-intervention period. Approximately $44 \%$ (37) of CR-BSI cases were diagnosed by clinical definition, $29 \%$ (25) by laboratory-confirmed definition, and $27 \%$ (23) by clinical and common skin contaminant definition. Among the symptoms of the 85 cases, $8 \%$ were febrile, $44 \%$ had apnoea, and $12 \%$ had bradycardia, but there were no significant differences among the symptoms of cases between the pre- and post-intervention periods (Table 4).

Among blood samples taken from the CR-BSI cases, 48 were positive, of which 33 and 15 samples were positive in the pre- and post-intervention periods, respectively. The most common causes in the pre-intervention period were Enterobacter spp. (30\%), Escherichia coli (30\%), and coagulase-negative staphylococci (30\%), while

Table 3 Catheter-related bloodstream infection rate in pre- and post-intervention periods in Hung Vuong Hospital, Vietnam

\begin{tabular}{lllll}
\hline Period & Cases & Catheter-days & $\begin{array}{l}\text { Rate/1000 } \\
\text { catheter-days }\end{array}$ & RR (95\% Cl) \\
\hline Pre-intervention & 53 & 8399 & 6.31 & 3.84 \\
Post-intervention & 32 & 8324 & 3.61 (0.39-0.94)
\end{tabular}

$R R$ rate ratio, $\mathrm{Cl}$ confidence interval Wald $\mathrm{x} 2$ statistics were used to test the significance of individual coefficients 
Table 4 Characteristics of neonates with catheter-related bloodstream infection in pre- and post-intervention periods in Hung Vuong Hospital, Vietnam

\begin{tabular}{|c|c|c|c|}
\hline Characteristics & $\begin{array}{l}\text { Pre-intervention } \\
\text { cases }(n=53)\end{array}$ & $\begin{array}{l}\text { Post-intervention } \\
\text { cases }(n=32)\end{array}$ & $\begin{array}{l}\text { Total } \\
(n=85)\end{array}$ \\
\hline \multicolumn{4}{|l|}{$\begin{array}{l}\text { Types of cases diagnosed blood stream infections } \\
\text { by case definitions (BSI, n, \%) }\end{array}$} \\
\hline Laboratory-confirmed BSI & $20(37.7)$ & $5(15.6)$ & $25(29.4)$ \\
\hline Clinical and common skin contaminant BSI & $13(24.5)$ & $10(31.2)$ & $23(27.1)$ \\
\hline Clinical BSI & $20(37.7)$ & $17(53.1)$ & $37(43.5)$ \\
\hline Fever $>38^{\circ} \mathrm{C}(\mathrm{n}, \%)$ & $5(9.4)$ & $2(6.2)$ & $7(8.2)$ \\
\hline Apnea $(\mathrm{n}, \%)$ & $21(39.6)$ & $16(50.0)$ & $37(43.5)$ \\
\hline Bradycardia (n, \%) & $7(13.2)$ & $3(9.4)$ & $10(11.8)$ \\
\hline Positive blood culture (n, \%) & $33(62.3)$ & $15(55.6)$ & $48(60.0)$ \\
\hline Coagulase-negative staphylococci & $10(30.3)$ & $2(13.3)$ & $12(25.0)$ \\
\hline Enterobacter (aerogenes, gergoviae, spp.) & $10(30.3)$ & $8(53.3)$ & $18(37.5)$ \\
\hline Escherichia coli & $10(30.3)$ & $3(20.0)$ & $13(27.1)$ \\
\hline Acinetobacter spp. & $2(6.1)$ & $0(0.0)$ & $2(4.2)$ \\
\hline Escherichia vulneris & $1(3.0)$ & $1(6.7)$ & $2(4.2)$ \\
\hline Stenotrophomonas maltophilia & $0(0.0)$ & $1(6.7)$ & $1(2.1)$ \\
\hline Episodes of hospital-acquired infection (mean, SD) & $1.47 \pm 0.67$ & $1.19 \pm 0.59$ & $1.36 \pm 0.65$ \\
\hline \multicolumn{4}{|l|}{ Status of discharge of cases $(n, \%)$} \\
\hline Death & $20(37.7)$ & $11(34.4)$ & $31(36.5)$ \\
\hline Cured & $30(56.6)$ & $20(62.5)$ & $50(58.8)$ \\
\hline Transferred & $3(5.7)$ & $1(3.1)$ & $4(4.7)$ \\
\hline $\begin{array}{l}\text { Days from intravenous catheter insertion to diagnosis } \\
\text { (mean, SD) }\end{array}$ & $7.11 \pm 5.45$ & $6.34 \pm 3.36$ & $6.82 \pm 4.76$ \\
\hline Days of hospitalization (mean, SD) & $33.9 \pm 39.2$ & $30.3 \pm 18.8$ & $32.5 \pm 32.9$ \\
\hline
\end{tabular}

$S D$ standard deviation

causes in post-intervention period were Enterobacter spp. (53\%) and Escherichia coli (20\%). Two cases (one in each of the stages) were positive for Escherichia vulneris; both received TPN via a catheter and were premature with gestational age at birth of 32 and 26 weeks and weight at birth of $1270 \mathrm{~g}$ and $900 \mathrm{~g}$, respectively. Six MDR Enterobacter spp. cases that were resistant to amoxicillin and clavulanate, ceftazidime, and ceftriaxone were confirmed. Episodes of HAI among CR-BSI cases in the post-intervention period decreased $(1.19 \pm 0.59$ vs. $1.47 \pm 0.67$ in the pre-intervention period). The proportion of dead CR-BSI cases in the post-intervention period was similar to that of the pre-intervention period. The mean of the number of days from catheter insertion to diagnosis and the mean of the number of days of hospitalisation in the post-intervention period were shorter than those in the pre-intervention period (Table 4).

Risk factors associated with catheter-related bloodstream infection cases in the pre- and post-intervention periods Among potential risk factors, preterm birth, hospital stays, duration of intravenous catheters, use of intravenous injection, use of endotracheal intubation, and use of umbilical catheter were associated with the CR-BSIs in univariate analysis. When applying logistic regression models in multivariate analysis, only days of intravenous catheter $(\mathrm{OR}=$ 1.05 , 95\% CI 1.03-1.08), use of endotracheal intubation $(\mathrm{OR}=2.27,95 \%$ CI 1.27-4.06), and intravenous injection $(\mathrm{OR}=8.50,95 \%$ CI 1.14-63.4) were still significant (Table 5). Results of the bootstrap replicates of the final model showed that the duration of the intravenous catheters was the most important variable, while the intravenous injection had the least effect in the final model.

\section{Discussion}

This study demonstrated that implementation of basic infection control interventions significantly reduced CRBSIs in NICU of a tertiary maternity hospital. The postintervention incidence rate was much lower than that of a study conducted at the HVH in 2007 (15.3 per 1000 catheter-days) and of a study conducted at Children's Hospital No. 1, Vietnam in 2005 (7.5 per 1000 catheterdays) $[12,13]$. Compared with neonatal care units in other countries, the post-intervention incidence rate in 
Table 5 Univariate and adjusted odds ratios for the association between risk factors and catheter-related bloodstream infection in Hung Vuong Hospital, Vietnam

\begin{tabular}{|c|c|c|c|c|}
\hline Risk factors & Cases $(n=85)$ & $\begin{array}{l}\text { Non-cases } \\
(n=2140)\end{array}$ & OR $(95 \% \mathrm{Cl})$ & Adjusted OR (95\% Cl) \\
\hline Gestational age (weeks) & $30.4 \pm 3.10$ & $34.5 \pm 3.62$ & $0.75(0.70-0.80)$ & $0.83(0.75-0.92)$ \\
\hline Gender (n, \%) & & & $0.98(0.63-1.51)$ & - \\
\hline Male & $47(55.3)$ & $1196(55.9)$ & & \\
\hline Female & $38(44.7)$ & $944(44.1)$ & & \\
\hline Weight at birth (gram) & $1451 \pm 468$ & $2242 \pm 766$ & $0.98(0.63-1.51)$ & - \\
\hline Preterm birth (n, \%) & $78(91.8)$ & $1359(63.5)$ & $6.40(2.94-13.95)$ & $0.93(0.27-3.18)$ \\
\hline Congenital diseases (n, \%) & $22(25.9)$ & $457(21.4)$ & $1.29(0.78-2.11)$ & - \\
\hline \multicolumn{5}{|l|}{ Methods of delivery (n, \%) } \\
\hline Cesarean section & $28(32.9)$ & $1005(47.0)$ & $0.55(0.35-0.88)$ & $0.96(0.54-1.71)$ \\
\hline Vaginal & $57(67.1)$ & $1135(53.0)$ & & \\
\hline Days of hospital stays & $33.0 \pm 33.2$ & $13.2 \pm 15.8$ & $2.79(2.78-2.81)$ & $1.01(0.99-1.02)$ \\
\hline Days of intravenous catheter & $19.7 \pm 11.0$ & $7.03 \pm 7.06$ & $3.03(2.96-3.09)$ & $1.05(1.03-1.08)$ \\
\hline Intravenous injection (n, \%) & $83(97.6)$ & $1527(71.4)$ & $16.7(4.09-67.9)$ & $8.50(1.14-63.4)$ \\
\hline Total parenteral nutrition (n, \%) & $85(100)$ & 2109 (98.6) & - & \\
\hline Use of endotracheal intubation ( $n, \%)$ & $49(57.6)$ & $338(15.8)$ & $7.26(4.65-11.3)$ & $2.27(1.27-4.06)$ \\
\hline Days of ventilator & $5.98 \pm 6.67$ & $3.71 \pm 7.30$ & $1.03(0.99-1.07)$ & - \\
\hline Use of umbilical intravenous catheter & $23(27.1)$ & $119(5.6)$ & $6.30(3.77-10.5)$ & $1.63(0.87-3.04)$ \\
\hline Days of using umbilical intravenous infusion & $8.13 \pm 5.48$ & $5.73 \pm 4.31$ & $1.10(0.99-1.22)$ & - \\
\hline
\end{tabular}

$O R$ odds ratio, $\mathrm{Cl}$ confidence interval

Wald $x 2$ statistics were used to test the significance of individual coefficients

this study was also lower than the rates of studies conducted in the Philippines during 2005-2009 and in Turkey in $2008[4,17]$. However, the rate after the intervention in our study was still higher than that of studies conducted in the developed countries, e.g. in the United States and Spain [18-21]. Although there were differences of the characteristics of neonates and catheter insertions in these studies (e.g. most neonates in our study were inserted by peripheral intravenous catheters and in a few cases with umbilical catheters), the rates of our study indicated that the intervention was effective, especially in resource-poor settings in Vietnam.

The effective intervention must have resulted from significant improvements in the nurses' knowledge and compliance with the CR-BSI preventive practices after the training. In a hand-hygiene-focused intervention in Brazil (2009), the rate of CR-BSI significantly decreased from 24.1 to 14.9 per 1000 catheter-days [22]. Several studies have shown that intensified training and educational programmes on hand hygiene and aseptic technique decreased the risk of CR-BSIs [20,21, 23-25]. Our study not only implemented education interventions, but also included other interventions, such as auditing and feedback of compliance with aseptic technique and reorganisation of TPN preparation by preparing it under a laminar airflow hood in a clean room in DOP as recommended by
WHO. The intervention probably led to a significant decrease of episodes of HAI among CR-BSI cases as well as hospital stays, number of deaths, and episodes of HAI among neonates with intravenous catheter insertions in the post-intervention period.

Most positive blood culture bacteria in our study were major common nosocomial pathogens that were consistent with other studies [8, 26, 27]. The decrease of coagulase-negative staphylococci, Enterobacter spp., Escherichia coli, and Acinetobacter spp. detected in blood samples in the post-intervention period highlights the effectiveness of BSI preventive practices, including auditing of and feedback about aseptic technique during care and maintenance of catheters [28]. Because of limited resources, we could not evaluate the effectiveness of each individual intervention. However, the types of interventions in our study may be appropriate for similar studies conducted in neonatal intensive care units in resource-poor settings.

Escherichia vulneris is usually found in wounds. It is an opportunistic pathogen and can cause sepsis followed by complicated diarrhoea [29]. Escherichia vulneris has rarely been reported as a CR-BSI pathogen. To our knowledge, only one CR-BSI case caused by Escherichia vulneris has been reported in the literature: the casepatient had poor nutritional status and received TPN via 
a central catheter [30]. In our study, we detected two cases, both premature neonates who received TPN via a catheter, that were positive for Escherichia vulneris. Hence, the pathogen should be suspected in premature neonates receiving TPN via a catheter. Enterobacter spp. was a common CR-BSI pathogen found on nurses' hands and MRDO [10, 31, 32]; however, the percentage of MDR Enterobacter spp. among reported CR-BSI pathogens was relatively high (13\%) compared with previous studies, and no CR-BSI MDR Enterobacter spp. was found in intensive care units in developing countries [31-33].

TPN is a controversial risk factor in the literature [34]. TPN was a critical risk factor of CR-BSI $[9,11]$, but it was not found to be a risk factor in our study, which is consistent with other studies $[35,36]$. This could be due to our intervention of relocating TPN preparation from DON to a clean room in DOP and preparing parenteral nutrition under a laminar airflow hood. Birth weight and preterm neonates have not been identified as risk factors in this study or in other studies $[9,35]$. Instead, we identified risk factors that included the days of intravenous catheters, intravenous injection, and the use of endotracheal intubation that were consistent with other studies $[19,25,35-37]$. Although the interventions in the study were shown to be effective, three risk factors are related directly to catheter usage. It is clear that catheter care and other BSI preventive practices should be regularly monitored and good practices should be maintained. The duration and types of catheters used for neonates need to be further studied.

\section{Conclusions}

The basic infection control interventions in this study had a major effect in reducing the incidence of CR-BSI in resource-poor settings. The BSI preventive practices, including auditing of and feedback to nurses, should be maintained, especially removing unnecessary intravenous catheters and stringently indicating the use of intravenous injection and endotracheal intubation to reduce the risk of CR-BSI.

\footnotetext{
Abbreviations

BSI: Bloodstream infection; CDC: Centers for Disease Control and Prevention; $\mathrm{Cl}$ : Confidence interval; CR-BSI: Catheter related bloodstream infections; DON: Department of Neonatal; DOP: Department of Pharmaceuticals; HAl: Hospital-acquired infections; HVH: Hung Vuong Hospital; MDR: Multidrug-resistant; MDRO: Multi-drug-resistant organisms; NICU: Neonatal intensive care unit; OR: Odds ratio; RR: Rate ratio; TPN: Total parenteral nutrition; WHO: World Health Organization
}

\section{Acknowledgements}

We would like to acknowledge the Infection Control Team of Hung Vuong Hospital in data collection.

\section{Authors' contributions}

Phan Thi Hang, Tran Thi Thuy Hang, Huynh Thi Ngoc Hanh, and Nguyen Thi Thu Hong contributed to conception, design, data collection, analysis and interpretation, drafting the manuscript.

Phan Thi Hang, Vo Huu Thuan, and Nguyen Van Truong contributed to data analysis and interpretation, critically drafting and revising the manuscript, and final approval of the version.

\section{Funding}

The study was supported by Hung Vuong Hospital. We have used no funding from private sources.

\section{Availability of data and materials \\ Available.}

\section{Ethics approval and consent to participate}

The study protocol was reviewed and approved by the Ethical Review Board of Hung Vuong Hospital. Written consent was obtained from all study surrogates.

\section{Consent for publication}

Obtained in the written consent including identities of individuals were kept confidential.

\section{Competing interests}

The authors have no conflicts of interest.

\section{Author details}

'Department of Infection Control, Hung Vuong Hospital, 128 Hong Bang Street, District 5, Ho Chi Minh City, Vietnam. ${ }^{2}$ Hung Vuong Hospital, 128 Hong Bang Street, District 5, Ho Chi Minh City, Vietnam.

Received: 17 April 2019 Accepted: 20 December 2019

Published online: 07 January 2020

\section{References}

1. O'Grady NP, Alexander M, Burns LA, Dellinger EP, Garland J, Heard SO, et al. Guidelines for the prevention of intravascular catheter-related infections. Clin Infect Dis. 2011;52:e162-e93.

2. Amira Ahmed IE. Ehssan Baghagho. Incidence of Nosocomial Infection Associated With Peripheral Venous and Umbilical Catheterization in Neonatal Intensive Care Unit Researcher. 2012:5:40-5.

3. Boyd S, Aggarwal I, Davey P, Logan M, Nathwani D. Peripheral intravenous catheters: the road to quality improvement and safer patient care. J Hosp Infect. 2011;77:37-41.

4. Bolat F, Uslu S, Bülbül A, Cömert S, Can E, Baş EK, et al. Hospital acquired bloodstream infections in neonatal intensive care unit. Turk Arch Ped. 2011; 46:130-6.

5. Frigerio S, Di Giulio P, Gregori D, Gavetti D, Ballali S, Bagnato S, et al. Managing peripheral venous catheters: an investigation on the efficacy of a strategy for the implementation of evidence-based guidelines. J Eval Clin Pract. 2012;18:414-9.

6. Daud-Gallotti RM, Costa SF, Guimarães T, Padilha KG, Inoue EN, Vasconcelos TN, et al. Nursing workload as a risk factor for healthcare associated infections in ICU: a prospective study. PLoS One. 2012;7:e52342.

7. Guembe M, Bustinza A, Sanchez Luna M, Carrillo-Alvarez A, Perez Sheriff V, Bouza E. Guidelines for preventing catheter infection: assessment of knowledge and practice among paediatric and neonatal intensive care healthcare workers. J Hosp Infect. 2012;81:123-7.

8. Ho TS, Wang SM, Wu YH, Shen CF, Lin YJ, Lin CH, et al. Long-term characteristics of healthcare-associated infections in a neonatal intensive care unit. J Microbiol Immunol Infect. 2010;43:407-15.

9. Holmes A, Dore CJ, Saraswatula A, Bamford KB, Richards MS, Coello R, et al. Risk factors and recommendations for rate stratification for surveillance of neonatal healthcare-associated bloodstream infection. J Hosp Infect. 2008; 68:66-72.

10. Larson EL, Cimiotti JP, Haas J, Nesin M, Allen A, Della-Latta P, et al. Gramnegative bacilli associated with catheter-associated and non-catheterassociated bloodstream infections and hand carriage by healthcare workers in neonatal intensive care units. Pediatr Crit Care Med. 2005;6:457-61. 
11. Mahieu LM, De Dooy JJ, Lenaerts AE, leven MM, De Muynck AO. Catheter manipulations and the risk of catheter-associated bloodstream infection in neonatal intensive care unit patients. J Hosp Infect. 2001;48:20-6.

12. Nguyen $T \mathrm{TH}, \mathrm{Cam} N \mathrm{~N}$, Nguyen HKT. Bloodstream infection: prevalence risk factors among patients related catheter insertions neonatal intensive care unit at Children's hospital no. 1. Ho Chi Minh: Ho Chi Minh City Infection Control Society; 2006.

13. Phan TH, Nguyen VT. Nosocomial infection in Department of Neonatal at hung Vuong hospital. Ho Chi Minh City J Med. 2010;14:157-62.

14. Horan TC, Andrus M, Dudeck MA. CDC/NHSN surveillance definition of health care-associated infection and criteria for specific types of infections in the acute care setting. Am J Infect Control. 2008;36:309-32.

15. The Centers for Disease Control and Prevention. Glossary of Terms Related to Antibiotic Resistance 2019 [updated 2019 Mar 15. Available from: https:// www.cdc.gov/narms/resources/glossary.html.

16. The Centers for Disease Control and Prevention. Multidrug-Resistant Organism \& Clostridioides difficile Infection (MDRO/CDI) Module 2019 [updated 2019 Jan. Available from: https://www.cdc.gov/nhsn/PDFs/ pscManual/12pscMDRO_CDADcurrent.pdf.

17. Navoa-Ng JA, Berba R, Galapia YA, Rosenthal VD, Villanueva VD, Tolentino MC, et al. Device-associated infections rates in adult, pediatric, and neonatal intensive care units of hospitals in the Philippines: International Nosocomial Infection Control Consortium (INICC) findings. Am J Infect Control. 39:548-54.

18. Maragakis LL, Bradley KL, Song X, Beers C, Miller MR, Cosgrove SE, et al. Increased catheter-related bloodstream infection rates after the introduction of a new mechanical valve intravenous access port. Infect Control Hosp Epidemiol. 2006;27:67-70.

19. Smith MJ. Catheter-related bloodstream infections in children. Am J Infect Control. 2008;36:S173 e1-3.

20. Perez Parra A, Cruz Menarguez M, Perez Granda MJ, Tomey MJ, Padilla B, Bouza E. A simple educational intervention to decrease incidence of central lineassociated bloodstream infection (CLABSI) in intensive care units with low baseline incidence of CLABSI. Infect Control Hosp Epidemiol. 2010;31:964-7.

21. Barsuk JH, Cohen ER, Feinglass J, McGaghie WC, Wayne DB. Use of simulation-based education to reduce catheter-related bloodstream infections. Arch Intern Med. 2009;169:1420-3.

22. Resende DS, JM O, Brito D, Abdallah VO, Gontijo Filho PP. Reduction of catheter-associated bloodstream infections through procedures in newborn babies admitted in a university hospital intensive care unit in Brazil. Rev Soc Bras Med Trop. 44:731-4.

23. Warren DK, Yokoe DS, Climo MW, Herwaldt LA, Noskin GA, Zuccotti G, et al. Preventing catheter-associated bloodstream infections: a survey of policies for insertion and care of central venous catheters from hospitals in the prevention epicenter program. Infect Control Hosp Epidemiol. 2006;27:8-13.

24. Rosenthal VD, McCormick RD, Guzman S, Villamayor C, Orellano PW. Effect of education and performance feedback on handwashing: the benefit of administrative support in Argentinean hospitals. Am J Infect Control. 2003; 31:85-92.

25. Safdar N, Kluger DM, Maki DG. A review of risk factors for catheter-related bloodstream infection caused by percutaneously inserted, noncuffed central venous catheters: implications for preventive strategies. Medicine (Baltimore). 2002;81:466-79.

26. Khan HA, Baig FK, Mehboob R. Nosocomial infections: epidemiology, prevention, control and surveillance. Asian Pac J Trop Biomed. 2017;7:478-82.

27. Pessoa-Silva CL, Richtmann R, Calil R, Santos RM, Costa ML, Frota AC, et al. Healthcare-associated infections among neonates in Brazil. Infect Control Hosp Epidemiol. 2004;25:772-7.

28. Goede MR, Coopersmith CM. Catheter-related bloodstream infection. Surg Clin North Am. 2009;89:463-74.

29. Jain S, Nagarjuna D, Gaind R, Chopra S, Debata P, Dawar R, et al. Escherichia vulneris: an unusual cause of complicated diarrhoea and sepsis in an infant. A case report and review of literature. New Microbes New Infect. 2016;13:83-6.

30. Spaulding AC, Rothman AL. Escherichia vulneris as a cause of intravenous catheter-related bacteremia. Clin Infect Dis. 1996;22:728-9.

31. Sievert DM, Ricks P, Edwards JR, Schneider A, Patel J, Srinivasan A, et al. Antimicrobial-resistant pathogens associated with healthcare-associated infections summary of data reported to the National Healthcare Safety Network at the Centers for Disease Control and Prevention, 2009-2010. Infect Control Hosp Epidemiol. 2013;34:1-14.

32. Weiner LM, Webb AK, Limbago B, Dudeck MA, Patel J, Kallen AJ, et al. Antimicrobial-resistant pathogens associated with healthcare-associated infections: summary of data reported to the National Healthcare Safety Network at the Centers for Disease Control and Prevention, 2011-2014. Infect Control Hosp Epidemiol. 2016;37:1288-301.

33. Rosenthal VD, Maki DG, Salomao R, Moreno CÁ, Mehta Y, Higuera F, et al. Device-associated nosocomial infections in 55 intensive care units of 8 developing countries. Ann Intern Med. 2006;145:582-91.

34. Gavin NC, Button E, Keogh S, McMillan D, Rickard C. Does parenteral nutrition increase the risk of catheter-related bloodstream infection? A systematic literature review. J Parenter Enter Nutr. 2017:41:918-28.

35. Yumani DF, van den Dungen FA, van Weissenbruch MM. Incidence and risk factors for catheter-associated bloodstream infections in neonatal intensive care. Acta Paediatr. 2013;102:e293-e8

36. Costa P, Paiva ED, Kimura AF, TEd C. Risk factors for bloodstream infection associated with peripherally inserted central catheters in neonates. Acta Paulista de Enfermagem. 2016;29:161-8.

37. Agarwal R, Gupta D, Ray P, Aggarwal AN, Jindal SK. Epidemiology, risk factors and outcome of nosocomial infections in a respiratory intensive care unit in North India. J Inf Secur. 2006;53:98-105.

\section{Publisher's Note}

Springer Nature remains neutral with regard to jurisdictional claims in published maps and institutional affiliations.
Ready to submit your research? Choose BMC and benefit from:

- fast, convenient online submission

- thorough peer review by experienced researchers in your field

- rapid publication on acceptance

- support for research data, including large and complex data types

- gold Open Access which fosters wider collaboration and increased citations

- maximum visibility for your research: over $100 \mathrm{M}$ website views per year

At $\mathrm{BMC}$, research is always in progress.

Learn more biomedcentral.com/submissions 